\title{
Glial-Derived Neurotrophic Factor Upregulates Expression of Functional SNS and NaN Sodium Channels and Their Currents in Axotomized Dorsal Root Ganglion Neurons
}

\author{
Theodore R. Cummins, Joel A. Black, Sulayman D. Dib-Hajj, and Stephen G. Waxman \\ Department of Neurology and Paralyzed Veterans of America and Eastern Paralyzed Veterans Association Neuroscience \\ Research Center, Yale Medical School, New Haven, Connecticut 06510, and Rehabilitation Research Center, Veterans \\ Affairs Connecticut Healthcare Center, West Haven, Connecticut 06516
}

\begin{abstract}
Dorsal root ganglion (DRG) neurons produce multiple sodium currents, including several different TTX-sensitive (TTX-S) currents and TTX-resistant (TTX-R) currents, which are produced by distinct sodium channels. We previously demonstrated that, after sciatic nerve transection, the levels of SNS and NaN sodium channel $\alpha$-subunit transcripts and protein in small (18-30 $\mu \mathrm{m}$ diameter) DRG neurons are reduced, as are the amplitudes and densities of the slowly inactivating and persistent TTX-R currents produced by these two channels. In this study, we asked whether glial-derived neurotrophic factor (GDNF), which has been shown to prevent some axotomy-induced changes such as the loss of somatostatin expression in DRG neurons, can ameliorate the axotomy-induced downregulation of SNS and NaN TTX-R sodium channels. We show here that exposure to GDNF can significantly increase both slowly inactivating and persistent TTX-R
\end{abstract}

sodium currents, which are paralleled by increases in SNS and NaN mRNA and protein levels, in axotomized DRG neurons in vitro. We also show that intrathecally administered GDNF increases the amplitudes of the slowly inactivating and persistent TTX-R currents, and SNS and NaN protein levels, in peripherally axotomized DRG neurons in vivo. Finally, we demonstrate that GDNF upregulates the persistent TTX-R current in SNS-null mice, thus demonstrating that the upregulated persistent sodium current is not produced by SNS. Because TTX-R sodium channels have been shown to be important in nociception, the effects of GDNF on axotomized DRG neurons may have important implications for the regulation of nociceptive signaling by these cells.

Key words: ion channel; neurotrophins; spinal sensory neurons; tetrodotoxin-resistant; nerve injury; persistent current
Small dorsal root ganglion (DRG) neurons (which include nociceptive neurons) are unusual in expressing tetrodotoxin-resistant (TTX-R) sodium currents, in addition to the TTX-sensitive (TTX-S) sodium currents that are present in many neurons (Kostyuk et al., 1981; Caffrey et al., 1992; Roy and Narahashi 1992). Because of their restricted expression patterns, which suggest a role in nociception, regulation of these TTX-R sodium currents, and the channels responsible for them, are of special interest.

Two distinct TTX-R sodium channel $\alpha$-subunits with different amino acid sequences have been identified in DRG neurons. The first, termed SNS (Akopian et al., 1996) or PN3 (Sangameswaran et al., 1996), is expressed in small-sized $(<30 \mu \mathrm{m}$ diameter $)$ and medium-sized (30-45 $\mu \mathrm{m}$ diameter) DRG neurons. The second, termed NaN (Dib-Hajj et al., 1998b, 1999a,b) or SNS2 (Tate et al., 1998), is expressed almost exclusively in small DRG neurons. Two distinct TTX-R sodium currents, referable to these channels, have recently been identified in DRG neurons. Patch-clamp studies on DRG neurons from SNS-null and wild-type mice have provided compelling evidence that: (1) SNS encodes the slowly inactivating TTX-R sodium current with a relatively depolarized voltage dependence of activation and inactivation in DRG neurons (Akopian et al., 1999), whereas (2) NaN produces a distinct TTX-R sodium

Received July 28, 2000; revised Sept. 21, 2000; accepted Sept. 21, 2000.

This work was supported in part by grants from the National Multiple Sclerosis Society and the Medical Research Service and Rehabilitation Research Service, Department of Veterans Affairs (S.G.W.). We also thank the Eastern Paralyzed Veterans Association and the Paralyzed Veterans of America for support. We thank W. Hormuzdiar and B. Toftness for excellent technical support, Drs. J. N. Wood and A. Akopian, University College London, for generously providing SNS-null mutant mice, and Dr. S. Tate, Glaxo-Wellcome Research and Development, for the gift of the SNS antibody.

Correspondence should be addressed to Dr. Stephen G. Waxman, Yale University School of Medicine, Department of Neurology, 707 LCI, 333 Cedar Street, New Haven, CT 06510. E-mail: Stephen.Waxman@Yale.Edu.

Copyright (C) 2000 Society for Neuroscience $0270-6474 / 00 / 208754-08 \$ 15.00 / 0$ current that has a relatively hyperpolarized voltage dependence of activation, a large overlap between activation and steady-state inactivation, and is persistent at negative potentials (Cummins et al., 1999). We refer to these two distinct TTX-R sodium currents as slow and persistent, respectively.

Transection of the axons of DRG neurons, within the sciatic nerve, decreases the amplitudes of both the slow and persistent TTX-R currents, and SNS and NaN message and protein, in small DRG neurons (Sleeper et al., 2000). By contrast, transection of the central projections (dorsal rhizotomy) of small DRG neurons does not alter slow or persistent TTX-R sodium current amplitudes or SNS or NaN protein levels (Sleeper et al., 2000). These observations suggest that peripheral growth factors could be involved in the regulation of DRG TTX-R sodium channels.

To determine whether growth factors modulate TTX-R channel expression, Fjell et al. (1999) exposed cultured DRG neurons to exogenously added nerve growth factor (NGF) or glial-derived neurotrophic factor (GDNF). NGF was found to increase SNS mRNA levels, but not NaN mRNA levels, at $7 \mathrm{~d}$ in vitro (7 DIV). By contrast, exogenous GDNF increased both SNS and NaN mRNA levels. GDNF also tended to increase a TTX-R current in cultured DRG neurons at DIV 7; however, the voltage-clamp protocols used in Fjell et al. (1999) were not appropriate for examining the persistent TTX-R current. Thus, the question of whether GDNF regulates expression of functional NaN and SNS channels in the cell membranes of DRG neurons has remained unanswered. In the present study we used the distinct physiological signatures of SNS and NaN currents (Cummins et al., 1999) to examine the expression of functional SNS and NaN channels in DRG neurons. In particular, we asked whether GDNF exposure can prevent the axotomy-induced reduction in slow and persistent TTX-R sodium currents, and in NaN and SNS protein, in DRG neurons in vitro and in vivo. 


\section{MATERIALS AND METHODS}

Surgery. Adult male rats were anesthetized with sodium pentobarbital (60 $\mathrm{mg} / \mathrm{kg}$ body weight), and the right sciatic nerves were exposed at the mid-thigh level, ligated with 4-0 silk sutures, transected, and the proximal stumps were placed in silicon cuffs to prevent regeneration (Waxman et al. 1994). Hydroxystilbamine methanesulfonate (4\% w/v; Molecular Probes, Eugene, OR), the active component of Fluorogold and a retrogradely transported fluorescent label, was placed in all cuffs before insertion of the nerve stump. The fluorescent label identified neurons that gave rise to axons that were transected. The contralateral DRGs served as controls. At the same time, an intrathecal cannula attached to an osmotic mini-pump (Alzet, Palo Alto, CA), which delivered $12 \mu \mathrm{g} / \mathrm{d}$ GDNF (Peprotech, Rocky Hill, NJ) to the lumbar enlargement, was implanted (Bennett et al., 1998).

Culture methods. Cultures of neurons were established from L4/L5 DRG of adult rats and SNS null mice (Akopian et al., 1999) as previously described (Rizzo et al., 1994). Briefly, lumbar ganglia (L4, L5) were excised, freed from their connective tissue sheaths, and incubated sequentially in enzyme solutions containing collagenase and then papain. The tissue was triturated in culture medium containing 1:1 DMEM and Hank's F-12 medium and $10 \%$ fetal calf serum, $1.5 \mathrm{mg} / \mathrm{ml}$ trypsin inhibitor, 1.5 $\mathrm{mg} / \mathrm{ml}$ bovine serum albumin, $100 \mathrm{U} / \mathrm{ml}$ penicillin, and $0.1 \mathrm{mg} / \mathrm{ml}$ streptomycin and plated on polyornithine-laminin-coated coverslips. The cells were maintained at $37^{\circ} \mathrm{C}$ in a humidified $95 \%$ air and $5 \% \mathrm{CO}_{2}$ incubator.

In experiments involving sciatic nerve ligation and intrathecal administration of GDNF, neurons derived from control L4/L5 DRG (nonaxotomized, non-GDNF administered), axotomized DRG without GDNF administration and axotomized DRG with intrathecal GDNF $(12 \mu \mathrm{g} / \mathrm{d}$ per animal) administration were harvested from rats $7 \mathrm{~d}$ after surgery and examined within $24 \mathrm{hr}$ of plating. Immunocytochemical analysis was performed on the same cultures used in patch-clamp investigation.

The method of Black et al. (1997), which provides an in vitro model of axotomy, was used for studying the effect of in vitro exposure to exogenously added GDNF; dissociation for culture shears off the axons of DRG neurons close to cell bodies in this model system and changes in sodium channel expression $7 \mathrm{~d}$ later mimic those seen after axotomy in vivo. L4/L5 DRG neurons from adult female Sprague Dawley rats and from SNS-null mice (Akopian et al., 1999) were dissociated and maintained in culture for $7-8 \mathrm{~d}(7 \mathrm{DIV})$ to examine the effects of in vitro exposure to GDNF. Half the coverslips from control adult rats, and from SNS-null mice, were treated with standard DRG medium, and half were treated with DRG medium supplemented daily with GDNF (human recombinant, $50 \mathrm{ng} / \mathrm{ml}$; Peprotech). The cells were fed daily for 7-8 d. The same cultures used in patch-clamp investigation were also used for immunocytochemical and RT-PCR analysis.

Whole-cell patch-clamp recordings. Sodium currents in small (18-30 $\mu \mathrm{m}$ diameter) DRG neurons were studied with whole-cell patch-clamp techniques at room temperature $\left(\sim 21^{\circ} \mathrm{C}\right)$ using an EPC -9 amplifier and the Pulse program (version 7.89). Fire-polished electrodes $(0.8-1.5 \mathrm{M} \Omega$ ) were fabricated from $1.7 \mathrm{~mm}$ capillary glass using a Sutter P-97 puller. The average access resistance was $1.6 \pm 0.6 \mathrm{M} \Omega$ for rat DRG neurons $(n=146)$ and $1.6 \pm 0.6 \mathrm{M} \Omega$ for SNS-null mice neurons $(n=137)$. Voltage errors were minimized using $80-85 \%$ series resistance compensation. Linear leak subtraction was used for all recordings. The pipette solution contained (in $\mathrm{mm}$ ): $140 \mathrm{CsF}, 1 \mathrm{EGTA}, 10 \mathrm{NaCl}$, and $10 \mathrm{HEPES}, \mathrm{pH}$ 7.3. The standard bathing solution was (in $\mathrm{mm}$ ): $140 \mathrm{NaCl}, 3 \mathrm{KCl}, 1 \mathrm{MgCl}_{2}, 1$ $\mathrm{CaCl}_{2}$, and $10 \mathrm{HEPES}, \mathrm{pH}$ 7.3. Cadmium $(100 \mu \mathrm{M})$ was included to block calcium currents, and $250 \mathrm{nM}$ TTX was included to block TTX-S sodium currents (Elliott and Elliott 1993; Cummins and Waxman, 1997). The osmolarity of all solutions was adjusted to $310 \mathrm{mOsm}$. Current densities were estimated by dividing the peak current amplitude by the cell capacitance. Small neurons that did not express TTX-R current were not excluded from the analysis. Peak current amplitude and current density mean values were calculated by averaging amplitude data from all of the small cells from which recordings were obtained.

Antibodies. Isoform-specific polyclonal antibodies generated against unique sequences of sodium channels $\mathrm{NaN}$ and SNS were used in these experiments. The generation and characterization of anti-NaN (Fjell et al. 2000) and anti-SNS (Black et al., 1999) sodium channel antibodies have been previously described.

Immunostaining. Coverslips with neurons derived from adult rat L4/L5 DRG and maintained in vitro for $7 \mathrm{~d}$ in the presence or absence of exogenously added GDNF, or from L4/L5 DRG after transection of the sciatic nerve with or without $7 \mathrm{~d}$ intrathecal administration of exogenous GDNF, were processed for immunocytochemistry as follows: (1) complete saline solution, $2 \times, 1$ min each; (2) $4 \%$ paraformaldehyde in $0.14 \mathrm{M}$ Sorensen's phosphate buffer, $10 \mathrm{~min}$; (3) PBS, $3 \times, 3$ min each; (4) PBS containing $5 \%$ normal goat serum, $2 \%$ bovine serum albumin, and $0.1 \%$ Triton X-100, $15 \mathrm{~min} ;(5)$ primary antibody (NaN, 1:500, in blocking solution; SNS, 1:100 in blocking solution), overnight at $4^{\circ} \mathrm{C}$; (6) $\mathrm{PBS}, 6 \times$ 5 min each; (7) secondary antibody (goat anti-rabbit IgG-Cy3, 1:3000); and (8) PBS, 6×, 5 min each.

Control experiments included incubation without primary antibody and preadsorption of the antibody with 100- to 500-fold molar excess of immunizing peptide. Only background levels of fluorescence were detected in the control experiments.

Quantitative analysis. A Leitz Aristoplan light microscope equipped with bright-field, Nomarski, and epifluorescence optics was used for sample observation. IPLab Spectrum program (Scanalytics) was used for image capture and analysis. For the in vitro model of axotomy with or without the administration of exogenous GDNF, two separate cultures were examined; for sciatic nerve transection and intrathecal administration of GDNF studies, three separate cultures for control (nonaxotomized, non-GDNF administration), two cultures for axotomized but without GDNF administration and four cultures for axotomized with intrathecal GDNF administration were examined. In these studies, only DRG neurons $<30 \mu \mathrm{m}$ diameter were included in the data analysis. Coverslips were scanned from the top left quadrant using bright-field optics with a nonoverlapping pattern, and the first 10-15 fields containing at least three identifiable small DRG neurons were captured. After capture of the bright-field image, appropriate fluorescent images were captured with Leica filter blocks N2.1 (Cy3) and D (hydroxystilbamine methanesulfonate). For the in vitro model of axotomy, 121 and 149 control neurons were analyzed for $\mathrm{NaN}$ and SNS immunolabeling, respectively, and 173 and 127 GDNF-treated neurons were examined for NaN and SNS immunostaining, respectively. For experiments involving intrathecal administration of GDNF, 170 and 130 control neurons, 79 and 118 axotomized without GDNF administration, and 87 and 86 axotomized with GDNF administration were examined for $\mathrm{NaN}$ and SNS immunostaining, respectively. Statistical comparisons were performed with a two-sample $t$ test using Microsoft Excel software.

$R N A$ preparation and $c D N A$ synthesis. Total RNA from cultured DRG cells was extracted using Qiagen (Hilden, Germany) RNeasy mini columns. Culture medium was aspirated from individual wells, replaced with lysis buffer, and cells were directly lysed by repeated pipetting. Lysate from one well was transferred to the next well, and extraction was repeated until the desired number of wells was processed. Six wells were used for each condition. An equal volume was then used to sequentially wash the processed wells, and the two fractions were combined for purification. The purified RNA was treated with RNase-free DNase-I (Roche Products, Hertforshire, UK) and re-purified over Qiagen RNeasy mini-column; RNA was eluted in $70 \mu$ l volume.

First strand cDNA was reverse-transcribed in a final volume of $10 \mu \mathrm{l}$ using $1 \mu \mathrm{l}$ of purified DNA-free total RNA, $1 \mathrm{~mm}$ random hexamer (Roche) 40 U of SuperScript II reverse transcriptase (Life Technologies, Gaithersburg, MD), and $40 \mathrm{U}$ of RNase Inhibitor (Roche). The buffer consisted of $50 \mathrm{~mm}$ Tris-HCl, pH 8.3, $75 \mathrm{~mm} \mathrm{KCl,} 3 \mathrm{mM} \mathrm{MgCl}, 10 \mathrm{~mm}$ DTT, and $5 \mathrm{~mm}$ dNTP. The reaction was allowed to proceed at $37^{\circ} \mathrm{C}$ for 90 $\mathrm{min}, 42^{\circ} \mathrm{C}$ for $30 \mathrm{~min}$, then terminated by heating to $65^{\circ} \mathrm{C}$ for $10 \mathrm{~min}$. A similar reaction mixture without the reverse transcriptase enzyme was prepared and used as a template to demonstrate absence of contaminating genomic DNA (data not shown).

Real-time PCR. The concept and validation of real-time quantitative PCR have been previously described (Gibson et al., 1996; Heid et al., 1996; Winer et al., 1999). We have used the relative standard curve method to study the effects of exposure to GDNF essentially as described in Sleeper et al. (2000).

\section{RESULTS}

\section{DRG neurons express separable slow and persistent TTX-R sodium currents}

When rat DRG neurons are studied after $<24 \mathrm{hr}$ in culture (1 DIV) with $250 \mathrm{~nm}$ TTX in the bathing solution, the majority (typically $\sim 85 \%$ ) of small ( $<30 \mu \mathrm{m}$ diameter) neurons exhibit TTX-R sodium currents. As Figure $1 A$ illustrates, both slow and persistent TTX-R currents are often observed when the cells are held at $-120 \mathrm{mV}$ for several minutes before applying the test depolarizations. When the cells are held at more depolarized potentials, such as $-50 \mathrm{mV}$, the persistent TTX-R current is attenuated by ultraslow inactivation (Cummins et al., 1999), and the slowly inactivating, or slow, TTX-R current predominates (Fig. $1 B)$. This slow TTX-R current is not observed in SNS-null mice (Akopian et al., 1999; Cummins et al., 1999) and therefore is dependent on expression of functional SNS sodium channel $\alpha$-subunits. If the currents obtained with the depolarized holding potential (Fig. $1 B$ ) are digitally subtracted from the currents obtained with the hyperpolarized holding potential (Fig. 1 $A$ ), the persistent TTX-R sodium current can be seen in relative isolation (Fig. 1C). In a representative group of 26 small neurons, $88 \%$ of the cells exhibited slow TTX-R currents, and $61 \%$ of the neurons exhibited persistent TTX-R currents. In this set of experiments, all of the cells exhibiting persistent TTX-R current also exhibited slow TTX-R current. The slow TTX-R current amplitude was $17.0 \pm 3.1$ $\mathrm{nA}$, and the persistent TTX-R current amplitude was $8.4 \pm 2.4 \mathrm{nA}$ in control 1 DIV neurons $(n=26)$ harvested from adult female rats. The slow and persistent TTX-R current densities were $667 \pm$ $135 \mathrm{pA} / \mathrm{pF}$ and $336 \pm 106 \mathrm{pA} / \mathrm{pF}$, respectively. 

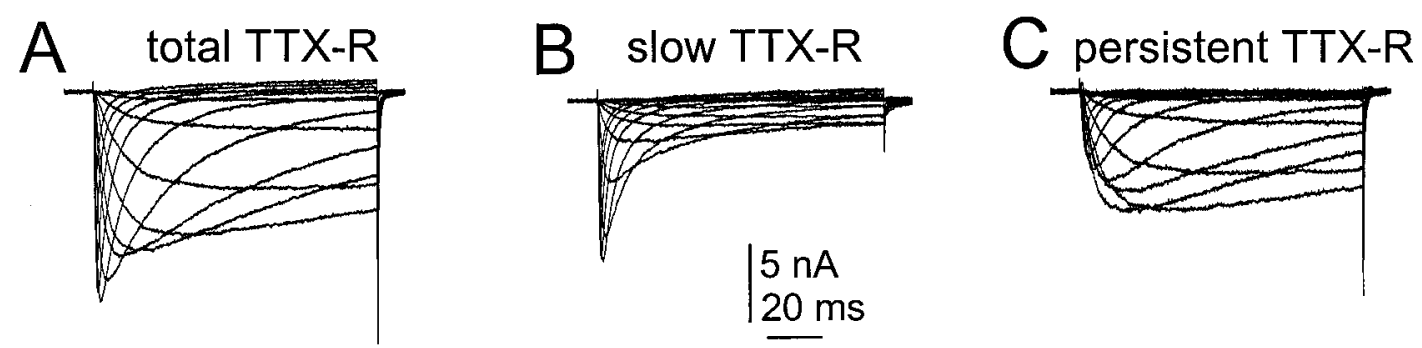

Figure 1. Multiple TTX-R sodium currents are expressed in rat small DRG neurons at 1 DIV. $A$, Representative recordings from a holding potential of $-120 \mathrm{mV}$. Calcium currents were blocked with $100 \mu \mathrm{M}$ cadmium in the bath solution, and TTX (250 nM) blocked the fast-inactivating currents. $B$, When the same neuron was held at $-50 \mathrm{mV}$ and a $500 \mathrm{msec}$ step to $-120 \mathrm{mV}$ preceded the test pulses, the persistent current was attenuated. $C$, Subtraction of the slow component $(B)$ from the total TTX-R current $(A)$ reveals the persistent current in rat DRG neurons.

A

Figure 2. Exposure to exogenously added GDNF in vitro increases TTX-R sodium currents. Families of voltage-activated TTX-R current traces recorded from representative rat DRG neurons without ( $A$, control $)$ and with $(B,+G D N F)$ exposure to GDNF after 7 DIV. Left, Representative recordings with a holding potential of $-120 \mathrm{mV}$. Middle, When the same neurons were held at $-50 \mathrm{mV}$, and a $500 \mathrm{msec}$ step to $-120 \mathrm{mV}$ preceded the test pulses, the persistent current was attenuated. Right, Subtraction of the slow component from the total TTX-R current reveals the persistent current in rat DRG neurons. GDNF was added to the culture medium at a concentration of $50 \mathrm{ng} / \mathrm{ml}$ for $7 \mathrm{~d}$. The currents were elicited by $100 \mathrm{msec}$ test pulses to potentials ranging from -80 to $+40 \mathrm{mV}$ in $5 \mathrm{mV}$ steps. Calcium currents were blocked with $100 \mu \mathrm{M}$ cadmium in the bath solution, and TTX (250 nM) blocked the fast-inactivating currents.

\section{DIV control}

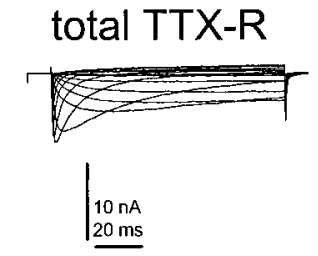

$B$

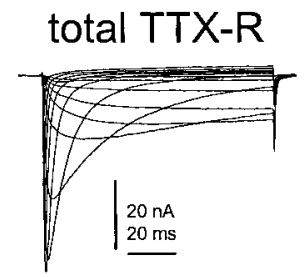

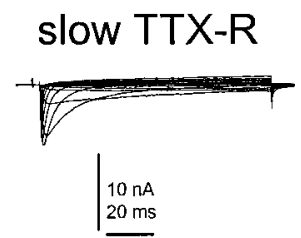

\section{DIV +GDNF}

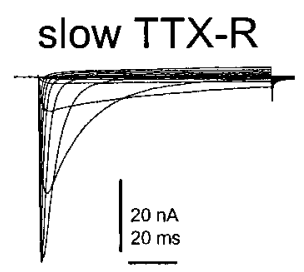

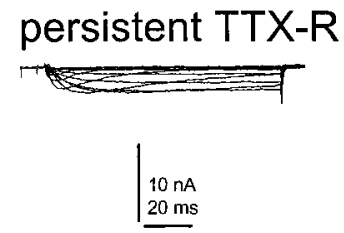

persistent TTX-R

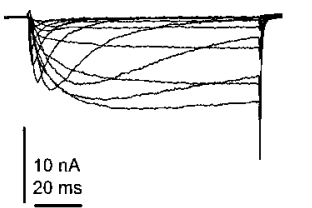

\section{Slow and persistent TTX-R sodium currents are smaller after 7-8 $d$ in culture}

We have recently shown that both slow and persistent TTX-R currents are greatly reduced in small L4 and L5 DRG neurons after transection of the sciatic nerve, but not after transection of their dorsal roots (Sleeper et al., 2000). SNS and NaN mRNA and protein levels exhibit parallel reductions after transection of the sciatic nerve (Dib-Hajj et al., 1996, 1998b; Sleeper et al., 2000). A similar decrease in SNS and NaN mRNA levels is observed in an in vitro model of axotomy, using cultured adult rat DRG neurons whose axons are sheared off close to the neuronal cell body during dissociation (Black et al., 1997; Fjell et al., 1999). Previous experiments have indicated that TTX-R current (not differentiated into slow and persistent) is also reduced after 7-8 $\mathrm{d}$ in culture (7 DIV; Fjell et al., 1999). However, these early experiments were performed before the demonstration (Cummins et al., 1999) that small DRG neurons express two distinct, slow and persistent, TTX-R currents. Moreover, because the persistent current is difficult to detect if the cells have not been maintained at negative (i.e., -120 $\mathrm{mV}$ ) holding potentials for several minutes, the earlier studies would not have determined whether the persistent TTX-R current decreases with time in culture. As Figure $2 A$ illustrates, both slow and persistent TTX-R currents are observed in small DRG neurons at 7 DIV. However, the amplitudes of these currents are significantly smaller compared with control neurons (see above) at 1 DIV. The slow TTX-R current amplitude is reduced to $8.3 \pm 2.0$ $\mathrm{nA}(p<0.05)$, and the persistent TTX-R current is reduced to $2.8 \pm 0.9 \mathrm{nA}(p<0.05)$ in small DRG neurons at 7 DIV $(n=28)$.
The densities of the TTX-R slow and persistent currents at 7 DIV were $244 \pm 47 \mathrm{pA} / \mathrm{pF}$ and $80 \pm 20 \mathrm{pA} / \mathrm{pF}$, respectively $(p<0.02$ compared with 1 DIV control neurons).

\section{GDNF increases amplitude of slow and persistent TTX-R currents in vitro}

To determine whether exogenously added GDNF modulates TTX-R current amplitudes, we examined TTX-R sodium currents in small DRG neurons that had been exposed to exogenously added GDNF (50 ng/ml replenished on a daily basis) for 7-8 $\mathrm{d}$ in vitro. By contrast to control 7 DIV neurons (without GDNF), GDNF-treated 7 DIV neurons exhibited large TTX-R sodium currents (Fig. 2B). The amplitudes of both slow and persistent TTX-R sodium currents were significantly increased by exposure to GDNF, to $29.7 \pm 3.9 \mathrm{nA}$ and $10.9 \pm 1.8 \mathrm{nA}$, respectively $(p<$ 0.001 ) compared with control 7 DIV neurons (Fig. 3). The amplitudes of the slow and persistent TTX-R sodium currents in the GDNF-treated 7 DIV neurons were equal to or larger than those observed for the 1 DIV neurons (Fig. 1). Although cells were selected based on soma diameter, the mean cell capacitance was significantly $(p<0.05)$ greater for 7 DIV neurons exposed to GDNF $(43 \pm 3 \mathrm{pF})$ than for control 7 DIV $(30 \pm 2 \mathrm{pF})$ or 1 DIV $(27 \pm 1, n=26)$ neurons. The increase in cell capacitance may be because of GDNF stimulation of neurite outgrowth. Despite this increase in cell capacitance, the densities of the slow and persistent TTX-R currents $(626 \pm 72 \mathrm{pA} / \mathrm{pF}$ and $227 \pm 40 \mathrm{pA} / \mathrm{pF}$, respectively) were also significantly $(p<0.002)$ increased compared with control 7 DIV neurons. 


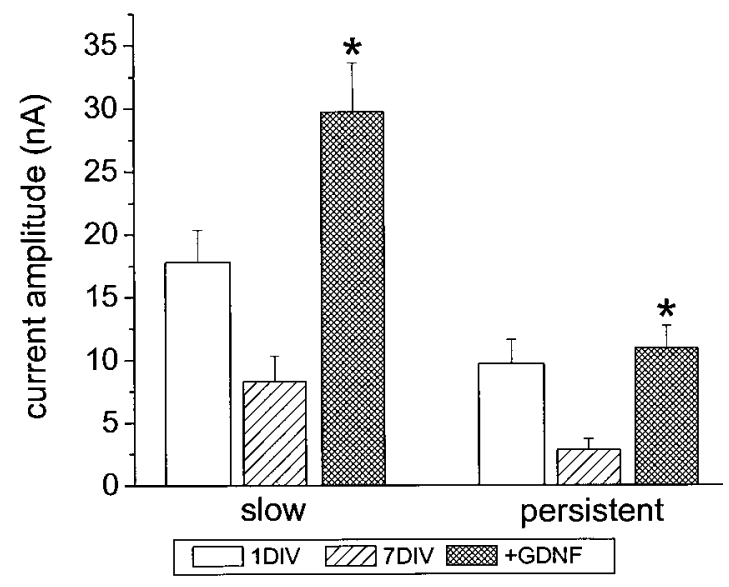

Figure 3. Slow and persistent TTX-R peak current amplitude from control and GDNF-treated neurons after 7 DIV are shown (mean \pm SE). For comparison, the slow and persistent TTX-R peak current amplitude measured at 1 DIV is also shown. GDNF treatment significantly increases $\left({ }^{*} p<0.001\right)$ the amplitude of both types of TTX-R current compared with the control 7 DIV neurons.

\section{GDNF increases SNS and NaN transcript and protein levels in vitro}

Previously we showed using in situ hybridization techniques that exposure to GDNF increases SNS and NaN mRNA expression in DRG neurons in vitro (Fjell et al., 1999). Using real-time quantitative PCR we confirm that GDNF significantly upregulates the expression of SNS and NaN genes in cultured DRG cells. Two independent sets of DRG cultures were analyzed for the effect of added GDNF for $7 \mathrm{~d}$ after culturing. Standard curves for the endogenous controls (18 S rRNA) and the Na channel targets were constructed using the appropriate primers/probe set (Table 1; Sleeper et al. 2000), and serial dilutions of transfected human embryonic kidney 293 cell line and P0 DRG cDNAs for NaN and SNS, respectively, were used as templates. The linear formula for the two standard curves for NaN quantitation were: $y=27.766-$ $2.939 x\left(R^{2}=0.993\right)$ for $\mathrm{NaN}$, and $y=19.36-3.082 x\left(R^{2}=0.984\right)$ for $18 \mathrm{~S}$ rRNA. The formulas for the two standard curves for SNS quantitation were: $y=30.653-2.864 x\left(R^{2}=0.987\right)$ for SNS, and $y=18.141-2.846 x\left(R^{2}=0.983\right)$ for $18 \mathrm{~S}$ rRNA. Samples of adult DRG cultures, with or without GDNF added to the medium for $7 \mathrm{~d}$, were amplified using the respective primers and probes (in separate reactions). The relative amounts of the $\mathrm{Na}$ channel targets were quantitated by linear extrapolation of the $C_{\mathrm{t}}$ values and were then normalized by the relative amounts of the endogenous control $18 \mathrm{~S}$ rRNA. The normalized values (no units) of the target sodium channels for treated and untreated samples for each experiment were then compared (Fig. 4).

Each set of cultures studied in this way displayed a GDNFinduced upregulation of both $\mathrm{NaN}$ and SNS mRNA. One set of cultures showed an upregulation of 6.6- and 6.3-fold of $\mathrm{NaN}$ and SNS transcripts, respectively, as a result of exposure to GDNF in the culture medium for $7 \mathrm{~d}$. The second culture showed an upregulation of 18.3- and 18.1-fold of NaN and SNS transcripts, respectively. GDNF clearly causes a significant upregulation of TTX-R sodium channel transcripts.

Because post-translational, as well as transcriptional control can regulate the levels of receptor and channel proteins (Sharma et al., 1993; Sucher et al., 1993), we also examined the effect of exogenously added GDNF on the expression of NaN and SNS protein levels using isoform-specific antibodies (Black et al., 1999; Fjell et al. 2000). As illustrated in Figure 5, exogenously added GDNF increased the immunostaining of both NaN and SNS compared with neurons maintained in culture without added GDNF. Quantitative analysis of $\mathrm{NaN}$ and SNS immunolabeling (from two sets of cultures) demonstrates that there is an approximately twofold increase in $\mathrm{NaN}$ and SNS signal intensities in GDNF-treated neurons compared with their respective control 7 DIV neurons (Fig. 6). This increase was significant $(p<0.05)$.

\section{Intrathecal GDNF partially rescues TTX-R currents in vivo}

Because in vitro exposure to GDNF restored both slow and persistent TTX-R sodium currents to control levels in cultured neurons, we asked whether GDNF treatment in vivo would rescue TTX-R sodium currents after peripheral axotomy. The sciatic nerve of adult male rats was transected, and $7 \mathrm{~d}$ intrathecal pumps containing either GDNF $(12 \mu \mathrm{g} / \mathrm{d})$ or vehicle (saline solution) were implanted. Seven days after surgery, the L4 and L5 DRG were harvested and cultured. Neurons were studied using whole-cell patch-clamp recordings within $24 \mathrm{hr}$ after dissociation. Axotomized neurons were identified by the retrograde uptake of the fluorescent tracer (see Materials and Methods). As Figure 7 illustrates, both slow and persistent TTX-R currents are significantly smaller in axotomized DRG neurons treated with vehicle only. The slow TTX-R current amplitude is reduced from $29.7 \pm 2.8 \mathrm{nA}(n=$ $48)$ in control 1 DIV DRG neurons to $6.2 \pm 1.3 \mathrm{nA}(n=52)$ in vehicle-treated axotomized 1 DIV neurons $(p<0.001)$. Slow TTX-R current density is reduced from $1020 \pm 85 \mathrm{pA} / \mathrm{pF}$ to $168 \pm$ $33 \mathrm{pA} / \mathrm{pF}(p<0.005)$. Similarly, the persistent TTX-R current amplitude is reduced from $18.5 \pm 2.1 \mathrm{nA}(n=48)$ in control 1 DIV neurons to $0.8 \pm 0.2 \mathrm{nA}(n=52)$ in vehicle-treated axotomized 1 DIV neurons $(p<0.001)$. Persistent TTX-R current density is reduced from $628 \pm 65 \mathrm{pA} / \mathrm{pF}$ to $23 \pm 5 \mathrm{pA} / \mathrm{pF}(p<0.005)$. The TTX-R sodium currents were larger in DRG neurons from animals with GDNF in the intrathecal pump (Fig. 7C). The amplitude of both slow and persistent TTX-R sodium currents were significantly increased by GDNF treatment, to $12.3 \pm 1.5 \mathrm{nA}$ and $5.3 \pm 0.8 \mathrm{nA}$, respectively $(p<0.01$ compared with vehicle-treated axotomized neurons; Fig. $7 D$ ). The leak currents were of similar amplitude in axotomized neurons with and without GDNF in the intrathecal pump.

Although cells were selected based on diameter measurements, the mean cell capacitance was significantly $(p<0.05)$ greater for neurons from animals with GDNF in the intrathecal pump (41 \pm 2 $\mathrm{pF})$ than for control neurons $(28 \pm 1 \mathrm{pF})$ or vehicle-treated axotomized neurons $(35 \pm 2)$. Even at $<24 \mathrm{hr}$ in culture, it appears that GDNF exposure increases neurite outgrowth. Despite the increased capacitance, the slow current density was increased to $274 \pm 30 \mathrm{pA} / \mathrm{pF}(p<0.05)$, and the persistent current density was increased to $138 \pm 26 \mathrm{pA} / \mathrm{pF}(p<0.005)$ for axotomized neurons exposed to intrathecal GDNF compared with vehicle-treated axotomized neurons. However, in contrast to the in vitro GDNF treatment, in vivo GDNF treatment did not fully restore the slow and persistent TTX-R sodium to the amplitudes or densities observed for control 1 DIV neurons.

\section{Intrathecal GDNF rescues SNS and NaN protein levels in vivo}

In parallel experiments, we also examined the effect of intrathecal administration of GDNF on the expression of SNS and $\mathrm{NaN}$ protein. For these experiments, three separate cultures of control (naïve animals) DRG, two cultures of axotomized DRG treated with vehicle only and four cultures of axotomized DRG treated with intrathecal GDNF were examined. Most small $(<30 \mu \mathrm{m}$ diameter) DRG neurons ( $<1$ DIV) from control rats exhibit robust $\mathrm{NaN}$ and SNS immunoreactivity (Fig. 8a,d). In contrast, $7 \mathrm{~d}$ after transection of the sciatic nerve there is a marked attenuation of $\mathrm{NaN}$ and SNS immunostaining in small DRG neurons treated with vehicle only (Fig. 8b,e). Intrathecal administration of GDNF markedly increases $\mathrm{NaN}$ and SNS immunolabeling in the axotomized neurons (Fig. 8c,f). Quantitative analysis of NaN and SNS immunofluorescence in control, axotomized, and axotomized with GDNF administration demonstrates that GDNF induces an approximately twofold increase in both NaN and SNS intensity compared with axotomized neurons without GDNF treatment (Fig. 9). This increase was significant $(p<0.05)$. 


\begin{tabular}{|c|c|c|c|}
\hline Gene & Forward primer & Reverse primer & Probe \\
\hline $\mathrm{NaN}$ & TGCCCTACCCACCTCACAAC & CCGGGCTAGTGAGCTGCTT & FAM-TTCAGGCCGGTGACCTCCCTCC-TAMRA \\
\hline SNS & TGGTCAACTGCGTGTGCAT & AATCAGAGCCTCGAAGGTGTAAA & $\begin{array}{l}\text { FAM-CCGAACTGATCTTCCAGAGAAAGTCGAG } \\
\text { TACGT-TAMRA }\end{array}$ \\
\hline
\end{tabular}

A

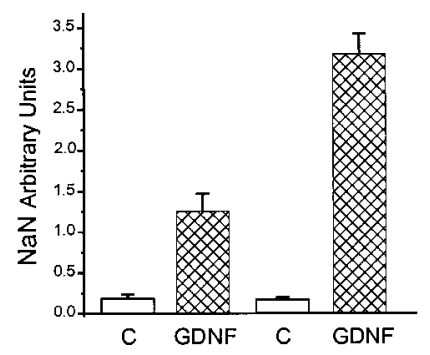

B

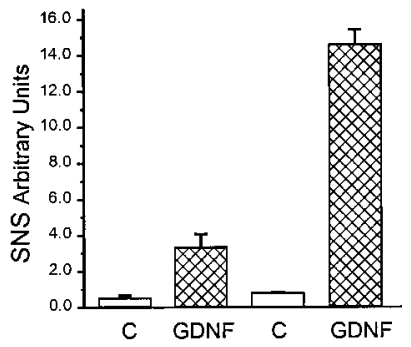

Figure 4. Increase in $\mathrm{Na}$ channel transcripts in two different cultures of adult DRG after treatment with GDNF for $7 \mathrm{~d}$, as measured by real-time RT-PCR (mean \pm SE). Effect of GDNF treatment on NaN $(A)$ and SNS $(B)$ expression normalized to the endogenous control $18 \mathrm{~S}$ rRNA. Each measurement was performed in quadruplet, and the relative amount of target was quantitated by the relative standard curve method.
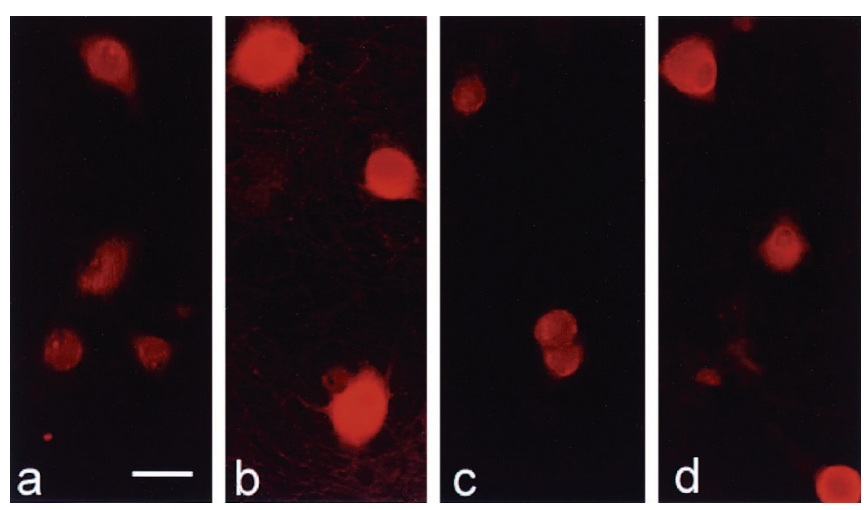

Figure 5. NaN and SNS sodium channel expression in DRG neurons. Cultured DRG neurons were maintained for $7 \mathrm{~d}$ in the absence $(A, C)$ or presence $(B, D)$ of exogenously added GDNF $(50 \mathrm{ng} / \mathrm{ml})$. The cultures were reacted with isoform-specific antibodies for $\operatorname{NaN}(A, B)$ or SNS $(C, D)$ Exogenously added GDNF substantially increases both NaN and SNS immunoreactivity in small DRG neurons compared with neurons maintained in the absence of exogenously added GDNF. Scale bar, $25 \mu \mathrm{m}$.

\section{GDNF increases persistent TTX-R currents in SNS-null mice DRG neurons}

Fjell et al. (1999) reported that whereas GDNF-treatment upregulates NaN mRNA expression in DRG neurons after 7 DIV, NGF treatment does not. Our data indicate that $\mathrm{NaN}$ underlies the persistent TTX-R sodium current in small DRG neurons (Cummins et al., 1999), and we have shown that exposure to GDNF increases the amplitude of the persistent TTX-R sodium current in rat DRG neurons in vitro (Figs. 2, 3) and in vivo (Fig. 7). To definitively demonstrate that the persistent current upregulated by GDNF treatment is not produced by SNS and to determine the effect of NGF treatment on the persistent TTX-R current, we examined the effects of NGF and GDNF on cultured DRG neurons from SNS-null mice. SNS-null mouse DRG neurons do not express the slow TTX-R current (Akopian et al., 1999; Cummins et al., 1999), but they do express the persistent TTX-R sodium current that is activated at negative potentials and that can be isolated from the slow TTX-R current in wild-type neurons using prepulse inac-

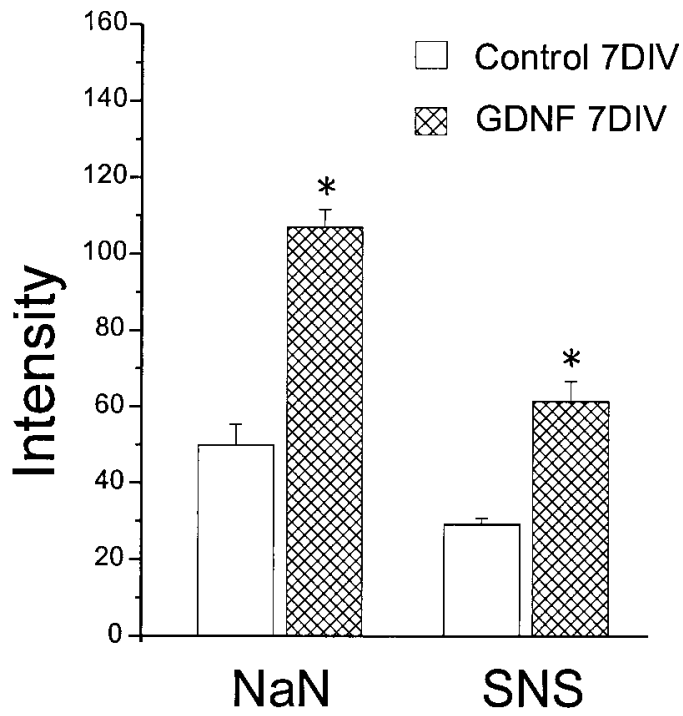

Figure 6. Quantification of NaN and SNS immunoreactivity in the presence and absence of exogenously added GDNF (mean \pm SE). Mean intensities of both $\mathrm{NaN}$ and SNS immunofluorescence are significantly $\left({ }^{*} p<0.05\right)$ increased in GDNF-treated neurons compared with control neurons.

tivation and digital subtraction (Cummins et al., 1999; Fig. 1). Because SNS-null neurons do not express the slow TTX-R current, the total TTX-R current recorded in SNS-null neurons is similar to that obtained in SNS-null neurons using prepulse inactivation and digital subtraction. Therefore prepulse inactivation and digital subtraction was not used for the recordings of the TTX-R currents in SNS-null neurons.

When examined by patch-clamp $<24 \mathrm{hr}$ in culture, $73 \%$ of small SNS-null DRG neurons expressed persistent TTX-R sodium current (mean amplitude $=5.1 \pm 0.7 \mathrm{nA} ; n=33$ ). As illustrated in Figure $10, A$ and $B$, the persistent current is greatly attenuated after $7 \mathrm{~d}$ in vitro; untreated SNS-null neurons expressed little or no TTX-R sodium current after 7 DIV (mean amplitude $=1.0 \pm 0.3$ $\mathrm{nA} ; n=39$ ). Exposure to GDNF significantly increased (mean amplitude $=5.7 \pm 0.6 \mathrm{nA} ; n=49 ; p<0.001$ ) the amplitude of the persistent TTX-R sodium current measured at 7 DIV (Fig. 10C). After in vitro exposure to GDNF, 68\% of the SNS-null mouse small neurons expressed persistent TTX-R sodium currents. In contrast, exposure to NGF did not increase the persistent TTX-R current (mean amplitude $=1.5 \pm 0.3 \mathrm{nA} ; n=34$; Fig. 10D).

The amplitude of the persistent current measured in the mouse SNS-null neurons exposed to GDNF (Fig. 10) was smaller than that measured in rat DRG neurons exposed to GDNF (Fig. 3). This raises the possibility that SNS channels might contribute to some of the persistent current observed in wild-type DRG neurons. However, Cummins et al. (1999) reported that the persistent current amplitude was similar in wild-type mouse DRG neurons and SNSnull neurons at 1 DIV, suggesting that SNS does not contribute to the persistent TTX-R current that is isolated in wild-type neurons using prepulse inactivation and digital subtraction. To further examine the hypothesis that SNS might contribute to the persistent TTX-R current in wild-type mouse neurons, we measured the amplitude of the persistent current in wild-type mouse DRG neurons after 7 DIV with and without exposure to GDNF. The 


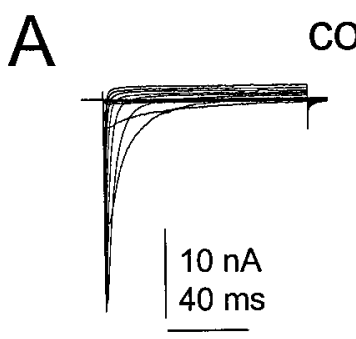

control

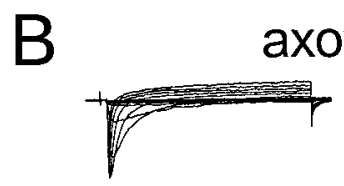

axotomized
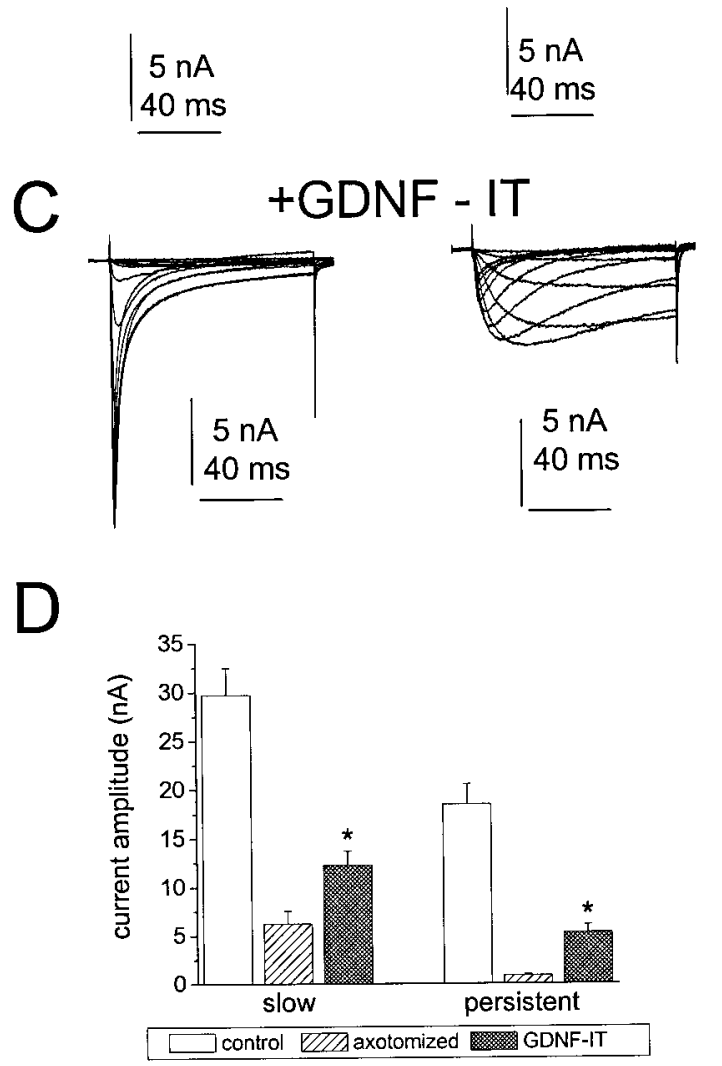

Figure 7. Intrathecal infusion of GDNF partially restores TTX-R sodium currents in vivo. $A-C$, Families of slow (left) and persistent (right) voltageactivated TTX-R current traces recorded from representative control $(A)$, vehicle-treated axotomized $(B)$, and GDNF-treated axotomized $(C)$ rat DRG neurons. Neurons were harvested $7 \mathrm{~d}$ after axotomy and studied at $<24 \mathrm{hr}$ in culture. Slow TTX-R currents were recorded with the neurons held at $-50 \mathrm{mV}$ and with a $500 \mathrm{msec}$ step to $-120 \mathrm{mV}$ preceded the test pulses (left). Subtraction of the slow component from the total TTX-R current recorded with a holding potential of $-120 \mathrm{mV}$ (data not shown) reveals the persistent current in rat DRG neurons (right). The currents were elicited by $100 \mathrm{msec}$ test pulses to potentials ranging from -80 to $+40 \mathrm{mV}$ in $5 \mathrm{mV}$ steps. Calcium currents were blocked with $100 \mu \mathrm{M}$ cadmium in the bath solution, and TTX $(250 \mathrm{~nm})$ blocked the fast-inactivating currents. $D$, Slow and persistent TTX-R peak current amplitude from control, vehicletreated axotomized, and GDNF-treated axotomized neurons are shown (mean $\pm \mathrm{SE})$. GDNF treatment significantly increases $(* p<0.01)$ the amplitude of both types of TTX-R current compared with the vehicletreated axotomized neurons.

amplitude of the persistent TTX-R sodium current, measured using prepulse inactivation and digital subtraction to remove the slow TTX-R current, was $5.8 \pm 0.9 \mathrm{nA}(n=51)$ at $1 \mathrm{DIV}, 0.9 \pm 0.3$ $\mathrm{nA}(n=28)$ without GDNF at $7 \mathrm{DIV}$, and $4.9 \pm 1.1 \mathrm{nA}(n=28)$ with GDNF exposure at 7 DIV. Therefore the amplitude of the persistent TTX-R current in wild-type mouse and SNS-null mouse
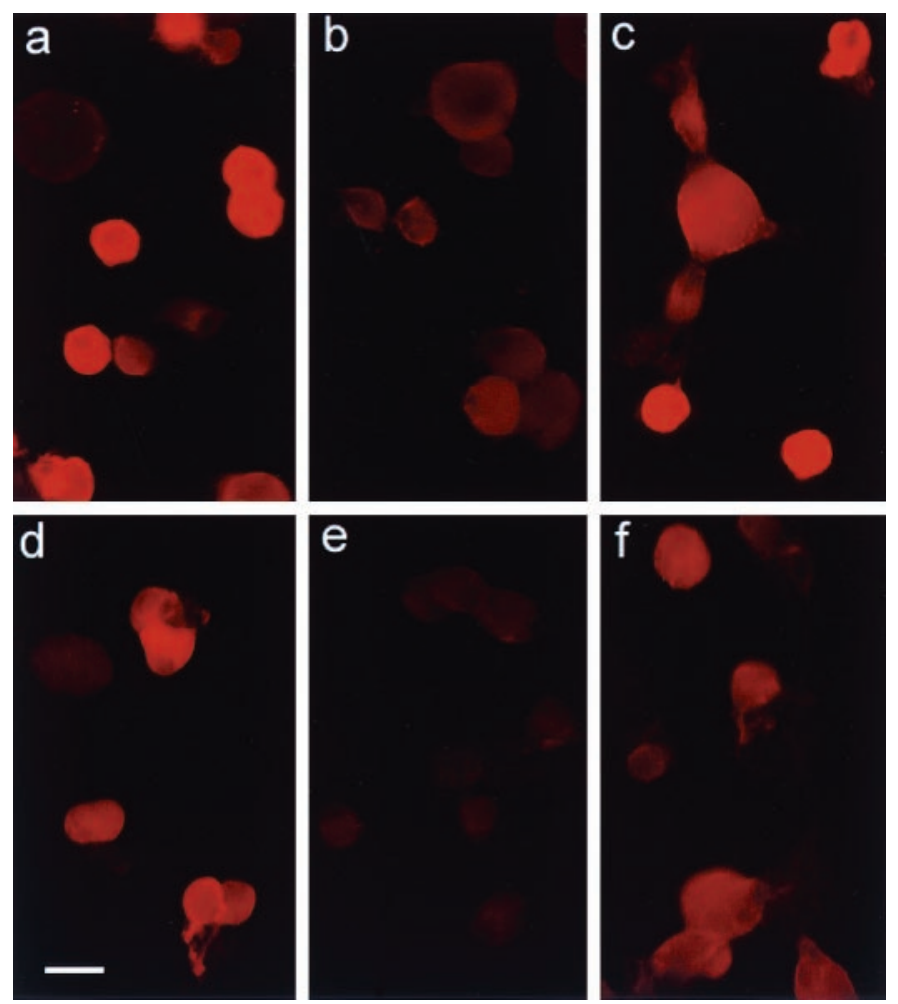

Figure 8. NaN and SNS sodium channel immunoreactivity in DRG neurons after intrathecal GDNF. Cultured DRG neurons derived from control $(a, d)$, axotomized $(b, e)$, and axotomized with intrathecal GDNF administration $(c, f)$ were reacted with isoform-specific antibodies for $\mathrm{NaN}(a-c)$ and SNS $(d-f)$. Peripheral axotomy causes an attenuation of $\mathrm{NaN}(b)$ and SNS $(e)$ immunoreactivity compared with uninjured control neurons $(a, d)$. Administration of intrathecal GDNF $(12 \mu \mathrm{g} / \mathrm{d})$ to peripherally axotomized DRG neurons rescues NaN $(c)$ and SNS $(f)$ expression. Scale bar, $25 \mu \mathrm{m}$.

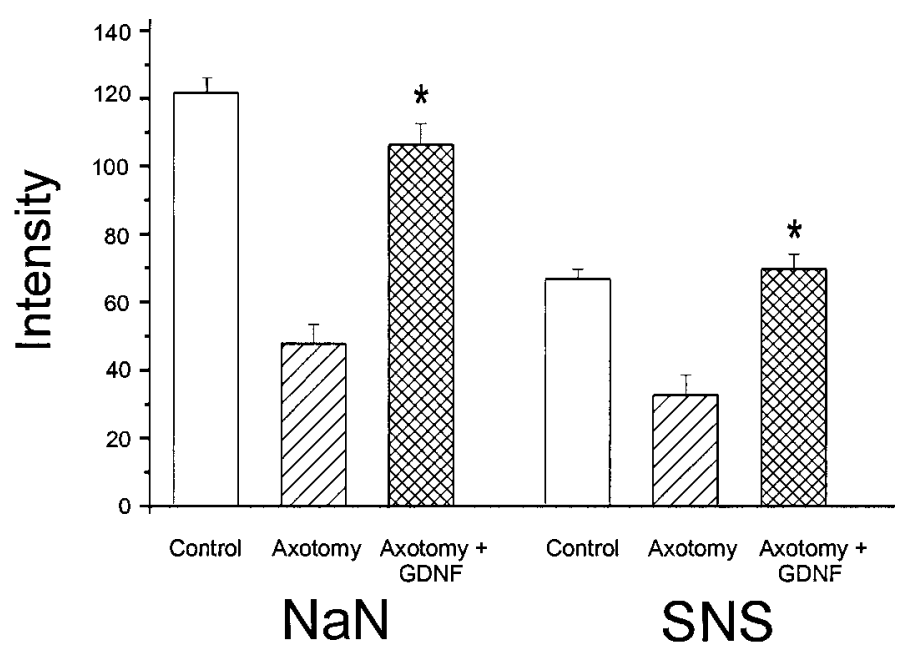

Figure 9. Quantification of NaN and SNS immunoreactivity in control DRG neurons and in axotomized DRG neurons with and without with intrathecal treatment. Intrathecal GDNF administration significantly $(p<$ 0.05 ) increases both $\mathrm{NaN}$ and SNS immunofluorescence (mean \pm SE) in axotomized neurons compared with axotomized neurons without GDNF treatment.

DRG neurons is similar at $1 \mathrm{DIV}$, decreases to $\sim 1 \mathrm{nA}$ after $7 \mathrm{DIV}$, and is restored to $\sim 6 \mathrm{nA}$ with exposure to GDNF. This data demonstrates that the persistent TTX-R sodium current that is activated at hyperpolarized potentials, is isolated in wild-type neurons using prepulse inactivation and digital subtraction, and is upregulated by GDNF in wild-type and SNS-null DRG neurons, is not generated by SNS. 

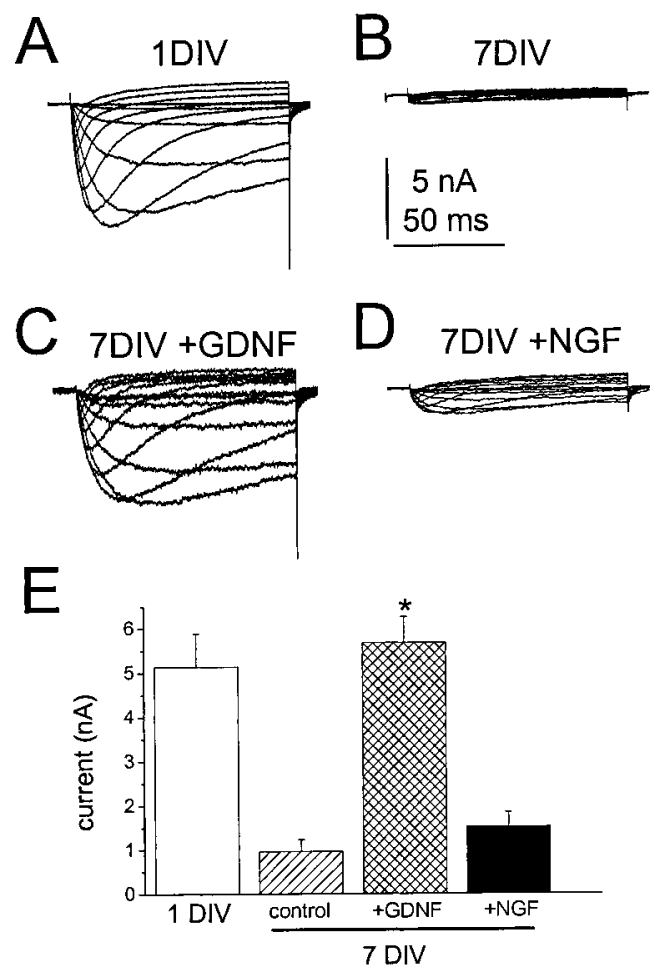

Figure 10. Representative TTX-R non-SNS currents in SNS-null neurons. $A, 1$ DIV. $B, 7$ DIV without exposure to GDNF. $C, 7$ DIV with exposure to GDNF. $D, 7$ DIV with exposure to NGF. $E$, Amplitudes of persistent TTX-R current from SNS-null mutant mouse DRG neurons with and without exposure to GDNF after 7 DIV are shown (mean \pm SE). For comparison, the TTX-R non-SNS current amplitude measured at $1 \mathrm{DIV}$ is also shown. Exposure to GDNF significantly $(* p<0.001)$ increases the amplitude of the persistent TTX-R current in SNS-null DRG neurons compared with the control and NGF-treated 7 DIV neurons. GDNF and NGF were added to the culture medium at a concentration of $50 \mathrm{ng} / \mathrm{ml}$ for $7 \mathrm{~d}$. The bath solution contained $250 \mathrm{nM}$ TTX. The currents were elicited by $100 \mathrm{msec}$ test pulses to potentials ranging from -80 to $+40 \mathrm{mV}$ in $5 \mathrm{mV}$ steps. Cells were held at $-100 \mathrm{mV}$.

\section{DISCUSSION}

In this study we show that GDNF upregulates two specific sodium channel $\alpha$-subunits and their currents in DRG neurons. DRG neurons are unique in expressing two distinct TTX-R sodium currents, which are produced by two distinct sodium channel $\alpha$-subunits, SNS (Akopian et al., 1996, 1999; Sangameswaran et al., 1996) and NaN (Cummins et al., 1999). Levels of both of these currents, and of the channels that produce them, are significantly reduced $7 \mathrm{~d}$ after axotomy of the sciatic nerve (Dib-Hajj et al., 1996, 1998b; Sleeper et al., 2000). However, dorsal rhizotomy did not alter the expression of these currents and channels (Sleeper et al., 2000), indicating that the reductions caused by peripheral axotomy is not simply an injury response. In this study we show that both channels, and their currents, are partially restored to control levels by intrathecal infusion of GDNF in vivo. GDNF infusion increased the amplitude of the slow current by twofold and the persistent current by more than sixfold compared with vehicletreated peripherally axotomized neurons. Exposure to GDNF in vitro restored both the slow and persistent TTX-R currents to control levels. Observations on the effect of GDNF on SNS-null and wild-type mouse DRG neurons, which do not express SNS or the slow TTX-R current, demonstrated that the GDNF-induced persistent TTX-R sodium current does not depend on the presence of functional SNS channels.

We have previously shown that axotomy-induced reductions in TTX-R sodium currents of small DRG neurons are paralleled by changes in specific sodium channel $\alpha$-subunit mRNAs; axotomy downregulates SNS and NaN mRNA (Dib-Hajj et al., 1996, 1998b). We have also shown that exposure to GDNF increases $\mathrm{NaN}$ and
SNS mRNA levels in cultured DRG neurons (Fjell et al., 1999). Using quantitative PCR techniques, we now show that exposure to GDNF in vitro increases NaN and SNS mRNA levels $~ 10$-fold compared with untreated 7 DIV cultures. Using immunocytochemical techniques we also show that (1) intrathecal inf usion of GDNF upregulates both SNS and NaN immunostaining by approximately twofold in vivo after sciatic nerve axotomy, and (2) exposure to GDNF in vitro similarly upregulates both SNS and NaN immunostaining by approximately twofold compared with untreated 7 DIV neurons. The difference between the RNA and immunostaining data could be because of post-translational control. Alternatively, it could reflect a difference in the sensitivity of the two assays. Irrespective of this, it is notable that GDNF upregulates mRNA, protein, and the currents associated with both SNS and $\mathrm{NaN}$ sodium channels.

The electrophysiological data from SNS-null neurons indicate that NaN encodes the persistent TTX-R sodium current in small DRG neurons (Cummins et al., 1999). Consistent with this conclusion, axotomy downregulates the persistent TTX-R current and NaN mRNA, and, as shown here, GDNF treatment upregulates the persistent TTX-R current and NaN protein and mRNA levels. Also consistent with the idea that $\mathrm{NaN}$ generates the persistent TTX-R sodium current, NGF does not upregulate either $\mathrm{NaN}$ mRNA (Fjell et al., 1999) or the persistent TTX-R sodium current (this study) in DRG neurons. Thus, NaN and the TTX-R persistent sodium current in DRG neurons are differentially regulated by the neurotrophins NGF and GDNF. Interestingly, NGF does appear to have an effect on the expression of SNS, and is known to upregulate SNS mRNA in vitro (Black et al., 1997) and in vivo (Dib-Hajj et al., 1998a). This differential response of SNS and NaN to neurotrophic factors is likely to contribute to the different patterns of expression of these TTX-R sodium channels in DRG neurons (Dib-Hajj et al., 1998b; Fjell et al., 1999).

The present results suggest that, like NGF (Ritter and Mendell, 1992; Mendell, 1995; Toledo-Aral et al., 1995), GDNF contributes to the regulation of the functional (electrophysiological) phenotype of small DRG neurons by differentially regulating TTX-R sodium channels. GDNF has been shown to prevent several axotomyinduced changes in small DRG neurons that are not affected by NGF. Bennett et al. (1998) demonstrated that intrathecal delivery of GDNF prevented the downregulation of somatostatin and thiamine monophosphatase expression, but not the downregulation of calcitonin gene-related peptide expression, that usually occurs after transection of the sciatic nerve. Munson and McMahon (1997) reported that GDNF can partially reverse the slowing of nerve conduction velocity that occurs after axotomy. Although the role of GDNF is poorly understood, several studies suggest that NGF and GDNF act on distinct subgroups of DRG neurons that have different functional roles (Kashiba et al., 1998; Stucky and Lewin, 1999). Stucky and Lewin (1999) found that isolectin $B_{4}\left(\mathrm{IB}_{4}\right)$ positive neurons, which most likely represent a GDNF-responsive population, have smaller heat-activated currents and longer duration action potentials than $\mathrm{IB}_{4}$-negative neurons. Furthermore, they showed that NGF, but not GDNF, increased the number of neurons that respond to noxious heat.

Although it is not yet entirely clear how the loss of slow and persistent TTX-R sodium currents impacts neuronal excitability, it is known that sensory neurons, including small DRG neurons, can become hyperexcitable and generate spontaneous impulses after injury in experimental animals and humans (Zhang et al., 1997). This inappropriate impulse activity may contribute to chronic pain. One hypothesis is that DRG neurons become hyperexcitable after nerve injury because of changes in sodium channel density or the characteristics of sodium currents, attributable at least in part to changes in the expression of sodium channel genes. We have shown that exposure to GDNF can maintain expression of two different TTX-R sodium channels and their currents in axotomized DRG neurons at levels close to control values, compared with untreated DRG neurons. Biophysical studies suggest that both SNS (Elliott, 1997; Schild and Kunze, 1997) and NaN (Cummins and Waxman, 
1997; Cummins et al., 1999) contribute to the regulation of excitability in neurons in which they are expressed. Moreover, physiological studies on axons demonstrate that TTX-R sodium channels contribute to action potential conduction in nonmyelinated C-fibers (Quasthoff et al., 1995; Brock et al., 1998). Our results may thus provide at least a partial explanation for the observation (Bennett et al., 1998) that intrathecally administered GDNF ameliorates the reduction in conduction velocity of $\mathrm{C}$-fibers that occurs after axotomy.

In summary, our results demonstrate, for the first time, that GDNF modulates the expression of two sodium channels, SNS and $\mathrm{NaN}$, and upregulates the number of functional SNS and $\mathrm{NaN}$ channels within DRG neurons after their axons are injured. Because abnormal sodium channel expression in DRG neurons may contribute to the pathogenesis of neuropathic pain, further study of the effects of GDNF may be relevant to the development of therapeutic strategies for pain after nerve injury.

\section{REFERENCES}

Akopian AN, Sivilotti L, Wood JN (1996) A tetrodotoxin-resistant voltage-gated sodium channel expressed by sensory neurons. Nature 379:257-262.

Akopian AN, Souslova V, England S, Okuse K, Ogata N, Ure J, Smith A, Kerr BJ, McMahon SB, Boyce S, Hill R, Stanfa LC, Dickenson AH, Wood JN (1999) The tetrodotoxin-resistant sodium channel SNS has a specialized function in pain pathways. Nat Neurosci 2:541-548.

Bennett DL, Michael GJ, Ramachandran N, Munson JB, Averill S, Yan Q, McMahon SB, Priestly JV (1998) A distinct subgroup of small DRG cells express GDNF receptor components and GDNF is protective for these neurons after nerve injury. J Neurosci 18:3059-3072.

Black JA, Langworthy K, Hinson AW, Dib-Hajj SD, Waxman SG (1997) NGF has opposing effects on $\mathrm{Na}^{+}$channel III and SNS gene expression in spinal sensory neurons. NeuroReport 8:2331-2335.

Black JA, Fjell J, Dib-Hajj S, Duncan ID, O’Connor LT, Fried K, Gladwell Z, Tate S, Waxman SG (1999) Abnormal expression of SNS/PN3 sodium channel in cerebellar Purkinje cells following loss of myelin in the taiep rat. NeuroReport 10:913-918.

Brock JA, McLachlan EM, Belmonte C (1998) Tetrodotoxin-resistant impulses in single nociceptor nerve terminals in guinea-pig cornea. $\mathrm{J}$ Physiol (Lond) 512:211-217.

Caffrey JM, Eng DL, Black JA, Waxman SG, Kocsis JD (1992) Three types of sodium channels in adult rat dorsal root ganglion neurons. Brain Res 592:283-297.

Cummins TR, Waxman SG (1997) Down-regulation of TTX-resistant sodium currents and upregulation of a rapidly repriming TTX-sensitive sodium current in small spinal sensory neurons after nerve injury. J Neurosci 17:3503-3514.

Cummins TR, Dib-Hajj SD, Black JA, Akopian AN, Wood JN, Waxman SG (1999) A novel persistent tetrodotoxin-resistant sodium current in small primary sensory neurons. J Neurosci 19:(RC43)1-6.

Dib-Hajj SD, Black JA, Felts P, Waxman SG (1996) Down-regulation of transcripts for $\mathrm{Na}$ channel $\alpha$-SNS in spinal sensory neurons following axotomy. Proc Natl Acad Sci USA 93:14950-14954.

Dib-Hajj SD, Black JA, Cummins TR, Kenney AM, Kocsis JD, Waxman SG (1998a) Rescue of $\alpha$-SNS sodium channel expression in small dorsal root ganglion neurons after axotomy by nerve growth factor in vivo. J Neurophysiol 79:2668-2678.

Dib-Hajj SD, Tyrrell L, Black JA, Waxman SG (1998b) NaN, a novel voltage-gated $\mathrm{Na}$ channel, is expressed preferentially in peripheral sensory neurons and down-regulated after axotomy. Proc Natl Acad Sci USA 95:8963-8968.

Dib-Haji SD, Tyrell L, Cummins TR, Black JA, Wood PM, Waxman SG (1999a) Two tetrodotoxin-resistant sodium channels in human dorsal root ganglion neurons. FEBS Lett 462:117-120.

Dib-Hajj SD, Tyrrell L, Escayg A, Wood PM, Meisler MH, Waxman SG (1999b) Coding sequence, genomic organization, and conserved chromosomal localization of the mouse gene scn11a encoding the sodium channel NaN. Genomics 59:309-318.

Elliott AA, Elliott JR (1993) Characterization of TTX-sensitive and TTX-resistant sodium currents in small cells from adult rat dorsal root ganglia. J Physiol (Lond) 463:39-56.

Elliott JR (1997) Slow Na+ channel inactivation and bursting discharge in a simple model axon: implications for neuropathic pain. Brain Res $754: 221-226$.
Fjell J, Cummins TR, Dib-Hajj SD, Fried K, Black JA, Waxman SG (1999) Differential role of GDNF and NGF in the maintenance of two TTX-resistant sodium channels in adult DRG neurons. Mol Brain Res 67:267-282.

Fjell J, Hjelmstrom P, Hormuzdiar W, Milenkovic M, Aglieco F, Tyrrell L, Dib-Hajj S, Waxman SG, Black JA (2000) Localization of the tetrodotoxin-resistant sodium channel NaN in nociceptors. NeuroReport 11:199-202.

Gibson UE, Heid CA, Williams PM (1996) A novel method for real time quantitative RT-PCR. Genome Res 6:995-1001.

Heid CA, Stevens J, Livak KJ, Williams PM (1996) Real time quantitative PCR. Genome Res 6:986-994.

Kashiba H, Hyon B, Senba E (1998) Glial cell line-derived neurotrophic factor and nerve growth factor receptor mRNAs are expressed in distinct subgroups of dorsal root ganglion neurons and are differentially regulated by peripheral axotomy in the rat. Neurosci Lett 252:107-110.

Kostyuk PG, Veselovsky NS, Tsyndrenko AY (1981) Ionic currents in the somatic membrane of rat dorsal root ganglion neurons. I. Sodium currents. Neuroscience 6:2423-2430.

Mendell LM (1995) Neurotrophic factors and the specification of neural function. Neuroscientist 1:26-34.

Munson JB, McMahon SB (1997) Effects of GDNF on axotomized sensory and motor neurons in adult rats. Eur J Neurosci 9:1126-1129.

Quasthoff S, Grosskreutz J, Schroder JM, Schneider U, Grafe P (1995) Calcium potentials and tetrodotoxin-resistant sodium potentials in unmyelinated $\mathrm{C}$ fibres of biopsied human sural nerve. Neuroscience 69:955-965.

Ritter AM, Mendell LM (1992) Somal membrane properties of physiologically identified sensory neurons in the rat: effects of nerve growth factor. J Neurophysiol 68:2033-2041.

Rizzo MA, Kocsis JD, Waxman SG (1994) Slow sodium conductances of dorsal root ganglion neurons: intraneuronal homogeneity and interneuronal heterogeneity. J Neurophysiol 72:2796-2815.

Roy ML, Narahashi T (1992) Differential properties of tetrodotoxinsensitive and tetrodotoxin-resistant sodium channels in rat dorsal root ganglion neurons. J Neurosci 12:2104-2111.

Sangameswaran L, Delgado SG, Fish LM, Koch BD, Jakeman LB, Stewart GR, Sze P, Hunter JC, Eglen RM, Herman RC (1996) Structure and function of a novel voltage-gated tetrodotoxin-resistant sodium channel specific to sensory neurons. J Biol Chem 271:5953-5956.

Schild JH, Kunze DL (1997) Experimental and modeling study of $\mathrm{Na}+$ current heterogeneity in rat nodose neurons and its impact on neuronal discharge. J Neurophysiol 78:3198-3209.

Sharma N, D’Arcangelo G, Kleinhous A, Halegaus S, Trimmer JS (1993) Nerve growth factor regulates the abundance and distribution of $\mathrm{K}^{+}$ channels in PC12 cells. J Cell Biol 123:1835-1845.

Sleeper AA, Cummins TR, Hormuzdiar W, Tyrell L, Dib-Hajj SD, Waxman SG, Black JA (2000) Changes in expression of two tetrodotoxinresistant sodium channels and their currents in dorsal root ganglion neurons following sciatic nerve injury, but not rhizotomy. J Neurosci 20:7279-7289.

Stucky CL, Lewin GR (1999) Isolectin B(4)-positive and -negative nociceptors are functionally distinct. J Neurosci 19:6497-6505.

Sucher NJ, Brose N, Dietcher DL, Awobuluyi M, Gasic GP, Bading H, Cepko CL, Greenberg ME, Jahn R, Heinemann SF, Lipton S (1993) Expression of endogenous NMDAR1 transcripts without receptor protein suggests post-transcriptional control in PC 12 cells. J Biol Chem 268:22299-22304.

Tate S, Benn S, Hick C, Trezise D, John V, Mannion RJ, Costigan M, Plumpton C, Grose D, Gladwell Z, Kendall G, Dale K, Bountra C, Woolf CJ (1998) Two sodium channels contribute to the TTX-R sodium current in primary sensory neurons. Nat Neurosci 1:653-555.

Toledo-Aral JJ, Brehm P, Halegoua S, Mandel G (1995) A single pulse of nerve growth factor triggers long-term neuronal excitability through sodium channel gene induction. Neuron 14:607-611.

Waxman SG, Kocsis JD, Black JA (1994) Type III sodium channel mRNA is expressed in embryonic but not adult spinal sensory neurons, and is reexpressed following axotomy. J Neurophysiol 72:466-470.

Winer J, Jung CK, Shackel I, Williams PM (1999) Development and validation of real-time quantitative reverse transcriptase-polymerase chain reaction for monitoring gene expression in cardiac myocytes in vitro. Anal Biochem 270:41-49.

Zhang J-M, Donnelly DF, Song X-J, LaMotte RH (1997) Axotomy increases the excitability of dorsal root ganglion cells with unmyelinated axons. J Neurophysiol 78:2790-2794. 